\title{
Articles
}

\section{Sulfhydryl Cotton Enrichment Separation-Determination of Silver in Geological Samples by ICP-MS}

\author{
Dan Li, ${ }^{*}$ Zhifei Zhao, Qin Chu, and Jindong Fang \\ Hubei Geology Research Laboratory. E-mail: leedaney@yahoo.com \\ Received February 17, 2011, Accepted August 1, 2011
}

\begin{abstract}
A rapid and inexpensive method was developed for the determination of trace silver in geological samples by using sulfhydryl cotton coupled with ICP-MS. The interferences such as ${ }^{90} \mathrm{Zr},{ }^{92} \mathrm{Mo}$ and ${ }^{93} \mathrm{Nb}$ on silver were investigated in detail. Sulfhydryl cotton was found to be an effective adsorbent for separation of interferences for $\mathrm{Ag}$ in the solutions. Excellent agreements with the certified values were obtained for all the certified reference materials. The memory effects of Ag by ICP-MS were examined by using different agents, including water, nitric acid, and HCl-thiourea to all standards/samples. The agents also acted as cleansing solutions. A combination of $\mathrm{HCl}$ with thiourea gave the minimum memory effect. For comparison of results, a proposed Chinese Geology Survey procedure DC-ARC-AES and a direct determination pretreatment method of ICP-MS (water bath- auqa regia digestion) were studied. Under optimal conditions, the detection limits of our method for ${ }^{107} \mathrm{Ag}$ and ${ }^{109} \mathrm{Ag}$ were $1.2 \mathrm{ng} / \mathrm{g}$ and $1.3 \mathrm{ng} / \mathrm{g}$, which offered much better accuracy for some difficult analysis geological samples such as GBW07604, GBW07605.
\end{abstract}

Key Words : Sulfhydryl cotton enrichment separation, ICP-MS, Trace silver

\section{Introduction}

The content of Ag is trace in geological samples especially for biology deposit, but they are used as an important index for better understanding of the elementary behavior and reveal the mechanisms of mineralization. Currently, there are many different techniques for micro Ag analysis. ${ }^{1-6} \mathrm{X}$ Ray Fluorescence (XRF) and inductively coupled plasma atomic emission spectrometry (ICP-AES) have been widely used to determine silver in geological samples. ${ }^{7,8}$ However, the detection limits cannot meet the requirement of trace Ag analysis. Compared with XRF and ICP-AES, GF-AAS ${ }^{9}$ offers better sensitivity, but the matrix effects increase the problems of accuracy. The most mature method of trace $\mathrm{Ag}$ analysis for geology survey nowadays is considered as DC Arc Atomic Emission Spectrometry (DC-ARC-AES) despite the detection limit of $\mathrm{Ag}$ is $20 \mathrm{ng} / \mathrm{g}$ besides time-consuming preparation procedures are needed. ${ }^{10}$ ICP-MS allows the rapid determination of trace levels of $\mathrm{Ag}$ in solutions, ${ }^{11}$ but there are still few publications have been devoted for geological samples and no ICP-MS method has been applied in geology survey. First, the memory effects are serious during the determination. ${ }^{12}$ In addition, before measurement, enrichment separation procedures usually needed such as using adsorbents. The activated carbon, polyamine sorbent, modified fiber n, foam, exchange resins and nano-materials are generally used. First, nano-materials are very costly. The absorption capacities of foam and exchange resins are not good enough for silver especially when $\mathrm{Fe}$ is present in the samples. Besides, according to our experiments, activated carbon, modified fiber and polyamine sorbent tend to absorb more interference. Thus, these adsorbents cannot separate interferences efficiently after separation. For instance, quantitication of ${ }^{107} \mathrm{Ag}$ has often interfered with ${ }^{91} \mathrm{ZrO},{ }^{90} \mathrm{Zr}^{16} \mathrm{OH}$ and quantitication of ${ }^{109} \mathrm{Ag}$ has usually interfered with ${ }^{93} \mathrm{Nb}^{16} \mathrm{O},{ }^{92} \mathrm{Zr}^{16} \mathrm{OH}$ and ${ }^{92} \mathrm{Mo}^{16} \mathrm{OH}$. Therefore, when the contributions of these interferences are large, it could lead to erroneous results. On the other hand, some paper ${ }^{13}$ reported direct determination of Ag by ICP-MS and the interferences can be partially reduced. Notwithstanding, without enrichment, the detection limit can't satisfy trace Ag analysis in some difficult analysis geological samples. Sulfhydryl cotton has been applied as an ideal enrichment separation adsorbent for micro amounts of Ag in early papers by using AAS and ICP-AES. They either employ some extremely poison regents like $\mathrm{KCN}^{14}$ or use complicate procedures to get rid of $\mathrm{Cl}^{-}$that has negative influence for the enrichment. ${ }^{15}$ To our knowledge, no sulfhydryl cotton enrichment separation method has been reported for determining trace $\mathrm{Ag}$ by combing with ICP-MS. In this work, the determination of trace Ag in geological samples by ICP-MS was studied after dissolution with three acids $\left(\mathrm{HCl}, \mathrm{HNO}_{3}\right.$, and $\left.\mathrm{HF}\right)$. The acids and other conditions are modified to effectively eliminate the interference and memory effect. A rapid, sensitive, inexpensive method by sulfhydryl cotton enrichment separation coupled with ICP-MS was developed. 
Table 1. Instrument Parameters of ICP-MS

\begin{tabular}{cccc}
\hline Parameters & Values & Parameters & Values \\
\hline Sweeps & $50 \mathrm{~s}$ & Cooling gas flow $(\mathrm{L} / \mathrm{min})$ & 14.0 \\
Auxiliary gas flow $(\mathrm{L} / \mathrm{min})$ & Ar, 1.5 & Carrier gas flow Ar (L/min) & 0.68 \\
Sample uptake rate $(\mathrm{mL} / \mathrm{min})$ & 1.48 & Scan mode & Peak Jumping \\
Integration time $(\mathrm{s})$ & 20 & Instrument DL $(\mathrm{ng} / \mathrm{mL})$ & $<0.01$ \\
Scan times & 2 & Sampling depth $(\mathrm{mm})$ & 8 \\
Resolution $(\mathrm{amu})$ & 0.86 & Sampler cone $(\mathrm{mm})$ & 1.0 \\
Nebulizer & Concentric type & Spray Chamber & Quartz \\
\hline
\end{tabular}

\section{Experiment}

Apparatus and Reagents. Twice distilled water was used. All regents were of ultrapure grade. Reference Materials were bought from National Standard Center (China). Stock standard solution of silver at a concentration of $1000 \mu \mathrm{g} / \mathrm{mL}$ was obtained from dissolving $0.1 \mathrm{~g}$ of pure $\mathrm{Ag}$ in $10 \mathrm{~mL}$ $\mathrm{HNO}_{3}$ and further diluted to $100 \mathrm{~mL}$ volumetric flask. HClthiourea solution was made by dissolving $2.5 \mathrm{~g}$ of thiourea by $500 \mathrm{~mL}$ of $0.4 \%$ (The concentration of all the agents are $\mathrm{V}: \mathrm{V}) \mathrm{HCl}$. Working standard solutions were obtained by appropriate dilution of the stock standard solutions step by step with HCl-thiourea solution. Internal standard solution was prepared by diluting corresponding concentrated stock solutions (made by HBGRL). An inductively coupled plasma mass spectrometer (Thermo, USA) was used.

ICP-MS Instrument Conditions. The operating conditions were optimized for maximum sensitivity on 24 elements especially for $\mathrm{Co}$, In, $\mathrm{U}$ (relatively stable and reflect the running condition of ICP-MS) and Ag. The complete working parameters are listed in Table 1 . The wash cycle between samples was optimized to ensure complete washout and equilibration of the entire system.

Preparation. To reduce the risk of contamination from ambient air and dust, all work was performed in a clean room. Before use, all regents and chemicals were checked for contamination. Vials were effectively cleaned by soaking in $\mathrm{HNO}_{3}\left(10 \%, 70^{\circ} \mathrm{C}, 10 \mathrm{~min}\right)$ and $\mathrm{HCl}$-thiourea solution $(2$ h). After that, the vials were rinsed with distilled water and dried at $50{ }^{\circ} \mathrm{C}$. All regents were checked for Ag background levels and only the regents that contain less than $0.05 \mathrm{ng} / \mathrm{mL}$ of $\mathrm{Ag}$ would be used. $\mathrm{HNO}_{3}$ was analyzed after an extra purification step by subboiling distillation.

\section{Enrichment Separation.}

Preparation of the Sulfhydryl Cotton Column: $50 \mathrm{~mL}$ of thioglycolic acid, $35 \mathrm{~mL}$ of acetic anhydride, $16 \mathrm{~mL}$ of $36 \%$ acetic acid, $0.5 \mathrm{~mL}$ of $98 \%$ sulfuric acid were added to $500 \mathrm{~mL}$ wide mouth bottle. After shaking the mixer well, 15 $\mathrm{g}$ of cotton was soaked in the mixer. Thereafter the cotton fiber was washed with distilled water until the washings were neutral. Finally, the cotton was transferred to another brown bottle dried at $40{ }^{\circ} \mathrm{C}$ for 4 days. Later, $0.2 \mathrm{~g}$ of the sulfhydryl cotton was filled in the tube of a funnel. The sulfhydryl cotton was washed with distilled water, followed with $2 \mathrm{~mL}$ of $50 \% \mathrm{HCl}$ three times. Afterwards the sulf- hydryl cotton was washed again with some distilled water until neutral. Ultimately, the column was conditioned with 2 $\mathrm{mL}$ of $2 \% \mathrm{HNO}_{3} 3$ times.

Sample Analysis: $0.5 \mathrm{~g}$ of geological reference materials including soils, sediments, and biological deposit were weighted in $30 \mathrm{~mL}$ Teflon vessels. The sample was first dissolved in $1 \mathrm{~mL} \mathrm{HClO}_{4}, 3 \mathrm{~mL} \mathrm{HNO}_{3}, 5 \mathrm{~mL} \mathrm{HF}$ with heating at $140{ }^{\circ} \mathrm{C}$ for 2 hours. Then the crucible covers were removed from the vessels. The temperature was subsequently set at $200{ }^{\circ} \mathrm{C}$ until $\mathrm{HF}-\mathrm{HClO}_{4}$ mixture was completely evaporated. During the heating, $1 \mathrm{~mL}$ of $2 \% \mathrm{HNO}_{3}$ was used to rinse the Teflon vessels 2 times. The residue was taken up by $2 \mathrm{~mL}$ of $50 \% \mathrm{HNO}_{3}$ and diluted with $10 \mathrm{~mL}$ of distilled water. The samples were heating again for 5 more minutes. Next $18 \mathrm{~mL}$ of distilled water were added and heated for another 5 minutes. Finally, $10 \mathrm{~mL}$ of distilled water was added and the mixer was stirred evenly with a glass rod.

The solutions were loaded onto the sulfhydryl cotton columns. Then columns were washed with $2 \% \mathrm{HNO}_{3}$ three times. A clean aurilave was used to squeeze the final solution of the columns. After that, the column was eluted with $2 \mathrm{~mL}$ of HCl-thiourea solution 5 times. The elution was collected by $10 \mathrm{~mL}$ colorimetric tubes. The solution obtained in the colorimetric tubes was ready for the determination by ICP-MS. On the other hand, with the matched matrix, the calibration samples were prepared by the above procedure and $0,5.0,10.0,20.0$, and $50.0 \mathrm{ng} / \mathrm{mL} \mathrm{Ag} \mathrm{were} \mathrm{used.} \mathrm{The}$ same procedure, but without any sample, was employed for the respective blank tests.

Table 2. Ion Interferences

\begin{tabular}{cccccc}
\hline & $\begin{array}{c}\text { Interference } \\
\text { ions } \\
\mathrm{ng} / \mathrm{mL}\end{array}$ & $\begin{array}{c}107 \mathrm{Ag} \\
\mathrm{ng} / \mathrm{mL}\end{array}$ & $\begin{array}{c}109 \mathrm{Ag} \\
\mathrm{ng} / \mathrm{mL}\end{array}$ & $\begin{array}{c}\text { Correction } \\
\text { factor } \\
107 \mathrm{Ag}\end{array}$ & $\begin{array}{c}\text { Correction } \\
\text { factor } \\
109 \mathrm{Ag}\end{array}$ \\
\hline \multirow{2}{*}{${ }^{92} \mathrm{Mo}$} & 1 & -0.002 & -0.002 & - & - \\
& 10 & 0.012 & 0.012 & - & - \\
\hline${ }^{93} \mathrm{Nb}$ & 100 & 0.013 & 0.046 & - & - \\
\hline & 2.5 & 0.005 & 0.007 & - & - \\
& 25 & 0.002 & 0.148 & - & 0.0059 \\
${ }^{90} \mathrm{Zr}$ & 10 & 0.006 & 1.433 & - & 0.0057 \\
& 40 & 0.000 & 0.019 & - & - \\
\hline & & 0.010 & 0.025 & - & - \\
\hline
\end{tabular}


Table 3. Residual of $\mathrm{Zr}$, Mo, $\mathrm{Nb}$

\begin{tabular}{ccccccc}
\hline Element & ${ }^{90} \mathrm{Zr}(\mathrm{ng} / \mathrm{mL})$ & $\begin{array}{c}\text { Certified value } \\
\text { of } \mathrm{Zr}\end{array}$ & ${ }^{92} \mathrm{Mo}$ & $\begin{array}{c}\text { Certified value } \\
\text { of Mo }\end{array}$ & $\begin{array}{c}{ }^{93} \mathrm{Nb} \\
\text { Certified value } \\
\text { of Nb }\end{array}$ \\
\hline Blank & 0.05 & 0 & 0.010 & 0 & 0.012 & 0 \\
GBW07103 & 6.5 & 167 & 0.015 & 3.5 & 0.010 & 40 \\
GBW07108 & 15 & 62 & 0.010 & 0.38 & 0.050 & 6.6 \\
GBW07408 & 7.6 & 490 & 0.010 & 1.16 & 0.000 & 15 \\
GBW07403 & 12 & 220 & 0.037 & 0.31 & 0.015 & 9.3 \\
GBW07305 & 31 & 220 & 0.005 & 1.2 & 0.051 & 19 \\
GBW07311 & 5.4 & 153 & 0.510 & 5.9 & 0.021 & 25 \\
\hline
\end{tabular}

\section{Results and Discussion}

\section{Interference Analysis.}

Interferences: Prior to analysis, the possibility of spectral interference was evaluated. To evaluate the spectral interferences, ${ }^{90} \mathrm{Zr}$, ${ }^{92} \mathrm{Mo}$ and ${ }^{93} \mathrm{Nb}$ contributions for ${ }^{107} \mathrm{Ag}$ and ${ }^{109} \mathrm{Ag}$ were measured with the addition of $\mathrm{Zr}$ solutions, $\mathrm{Nb}$ solutions and Mo solutions to $0 \mathrm{ng} / \mathrm{mL}$ of $\mathrm{Ag}$ solution. The results are shown in Table 2. It can be seen that Ag isotopes would not be freed from the interferences if the concentrations of $\mathrm{Zr}$, Mo or $\mathrm{Ag}$ are much higher than the studied concentrations. However, less than $100 \mathrm{ng} / \mathrm{mL}$ of ${ }^{92} \mathrm{Mo}$ has little interference effect for both ${ }^{107} \mathrm{Ag}$ and ${ }^{109} \mathrm{Ag}$. On the other hand, more than $25 \mathrm{ng} / \mathrm{mL}$ of ${ }^{93} \mathrm{Nb}$ for ${ }^{109} \mathrm{Ag}$ and more than $40 \mathrm{ng} / \mathrm{mL}$ of ${ }^{90} \mathrm{Zr}$ for ${ }^{107} \mathrm{Ag}$ could be corrected by subtracting the interference factors multiplied by the concentration.

The Residual of Interferences: Some soil reference materials, GBW07403, GBW07408, sediment reference materials, GBW07305, GBW07311 and rock reference materials, GBW07103, GBW07108 were randomly selected for the residual test. The ICP-MS determination results for the interferences of the digested solution after the sulfhydryl cotton enrichment separation were described in Table 3. It can be seen the interferences on the isotopes are significantly decreased with the analytical procedure compared to the certified values. The residuals of Mo and $\mathrm{Nb}$ are less than 1 $\mathrm{ng} / \mathrm{mL}$ and the residual of $\mathrm{Zr}$ is less than $40 \mathrm{ng} / \mathrm{mL}$. Therefore ${ }^{90} \mathrm{Zr}$ in samples like GBW07305 only gently interfere with ${ }^{107} \mathrm{Ag}$ when the content of $\mathrm{Ag}$ is very low. However, the residuals in the final solution have no interference for ${ }^{109} \mathrm{Ag}$. Thus, complex interference corrections were not required for geology samples by using this method if ${ }^{109} \mathrm{Ag}$ was studied.

Memory Effect. Three reagents, including water, $2 \%$ $\mathrm{HNO}_{3}, \mathrm{HCl}$-thiourea Solution were evaluated according to the memory effect. For each reagent, an equivalent blank and a $100 \mathrm{ng} / \mathrm{mL}$ standard solution was analyzed. The time response in regent Blank for ${ }^{107} \mathrm{Ag}$ and ${ }^{109} \mathrm{Ag}$ was monitored after the introduce of $100 \mathrm{ng} / \mathrm{mL} \mathrm{Ag}$ standard solution into the instrument for about $50 \mathrm{~s}$. First, the concentration was recorded while washing with water until it changed to background value and almost became constant. Then $100 \mathrm{ng} / \mathrm{mL}$ of $\mathrm{Ag}$ standard solution with another matrix $\left(2 \% \mathrm{HNO}_{3} /\right.$ $\mathrm{HCl}$-thiourea) was injected to ICP-MS, and the corresponding reagent blank was measured with the same procedure but

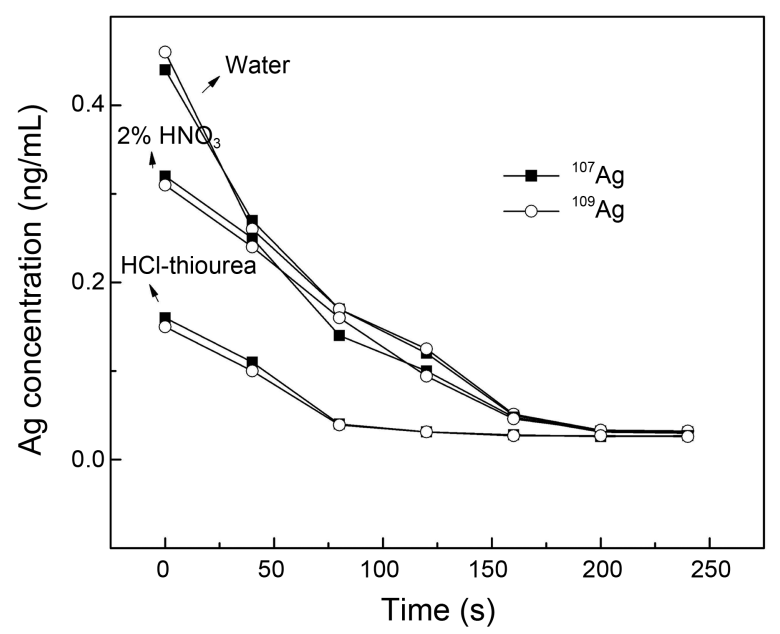

Figure 1. Memory Effect.

washed with $2 \% \mathrm{HNO}_{3} / \mathrm{HCl}$-thiourea. Figure 1 gives the time response for the selected reagents. The results show water and $2 \% \mathrm{HNO}_{3}$ exhibit similar significant memory effects. However, the memory effect was reduced in $\mathrm{HCl}$ thiourea medium since the time response was shorter. This may be because acidified thiourea solution cleans the residues of $\mathrm{Ag}$ better in spray chamber and the injection tubes.

Precision Study. The use of internal standard for determination of trace amounts of $\mathrm{Ag}$ in geological samples was

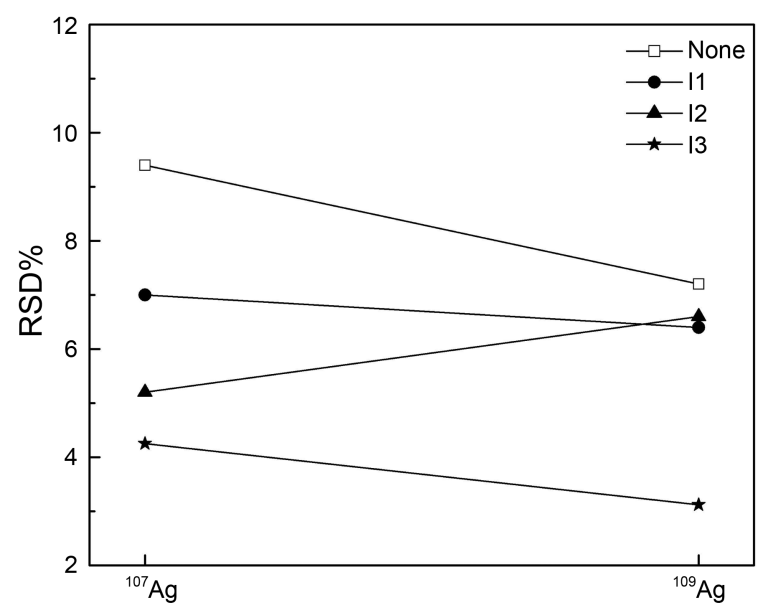

Figure 2. Comparison of the Internal Standards. 
Table 4. Precision Test

\begin{tabular}{ccccccccccccc}
\hline Samples & \multicolumn{2}{c}{ GBW07401 } & \multicolumn{2}{c}{ GBW07402 } & \multicolumn{2}{c}{ GBW07103 } & \multicolumn{2}{c}{ GBW07104 } & \multicolumn{2}{c}{ GBW07604 } & GBW07605 \\
\hline Element & $107 \mathrm{Ag}$ & $109 \mathrm{Ag}$ & $107 \mathrm{Ag}$ & $109 \mathrm{Ag}$ & $107 \mathrm{Ag}$ & $109 \mathrm{Ag}$ & $107 \mathrm{Ag}$ & $109 \mathrm{Ag}$ & $107 \mathrm{Ag}$ & $109 \mathrm{Ag}$ & $107 \mathrm{Ag}$ & $109 \mathrm{Ag}$ \\
\hline & 0.291 & 0.292 & 0.047 & 0.048 & 0.022 & 0.024 & 0.078 & 0.075 & 0.012 & 0.014 & 0.019 & 0.017 \\
& 0.301 & 0.306 & 0.048 & 0.049 & 0.023 & 0.024 & 0.079 & 0.079 & 0.012 & 0.015 & 0.020 & 0.021 \\
& 0.366 & 0.364 & 0.044 & 0.043 & 0.021 & 0.023 & 0.079 & 0.076 & 0.014 & 0.015 & 0.017 & 0.021 \\
Test & 0.366 & 0.368 & 0.044 & 0.045 & 0.022 & 0.025 & 0.080 & 0.078 & 0.015 & 0.013 & 0.021 & 0.019 \\
Results & 0.374 & 0.370 & 0.041 & 0.040 & 0.024 & 0.022 & 0.078 & 0.075 & 0.013 & 0.015 & 0.020 & 0.021 \\
& 0.363 & 0.364 & 0.039 & 0.040 & 0.023 & 0.024 & 0.075 & 0.072 & 0.012 & 0.014 & 0.019 & 0.019 \\
& 0.367 & 0.365 & 0.044 & 0.044 & 0.021 & 0.026 & 0.079 & 0.079 & 0.015 & 0.014 & 0.016 & 0.017 \\
& 0.362 & 0.361 & 0.045 & 0.045 & 0.022 & 0.022 & 0.070 & 0.076 & 0.014 & 0.011 & 0.018 & 0.020 \\
\hline Average & 0.349 & 0.349 & 0.044 & 0.044 & 0.022 & 0.024 & 0.077 & 0.076 & 0.0134 & 0.0139 & 0.0188 & 0.0194 \\
RSD\% & 9.44 & 8.90 & 6.74 & 7.43 & 4.65 & 5.85 & 4.25 & 3.12 & 2.88 & 9.77 & 8.90 & 8.70 \\
\hline
\end{tabular}

investigated.Three solutions, I1 ( $2 \mathrm{ng} / \mathrm{mL}$ of $\mathrm{Rh}, \mathrm{Re}, 1 \%$ $\left.\mathrm{HNO}_{3}\right), \mathrm{I} 2\left(2 \mathrm{ng} / \mathrm{mL}\right.$ of $\left.\mathrm{Rh}, 1 \% \mathrm{HNO}_{3}\right)$, and $\mathrm{I} 3(2 \mathrm{ng} / \mathrm{mL}$ of $\mathrm{Rh}, \mathrm{HCl}$-thiourea mixed solution) were investigated. The internal Standard was added on-line to all solutions. Each internal standard was tested for the precision of the same Ag reference material, GBW07104, as was shown in Figure 2. The results demonstrated that $2 \mathrm{ng} / \mathrm{mL} \mathrm{Rh}$, HCl-thiourea internal standard could improve the accuracy of $\mathrm{Ag}$ result.

The accuracy of the analytical procedure was then verified by comparing recognized measurements with certified values for the soil reference materials, GBW07401, GBW07402, rock reference materials, GBW07103, GBW07104. Because there is a lack of adequate reference materials with certified ultralow concentrations of $\mathrm{Ag}$, two biology reference materials, GBW07604, GBW07605 were studied. The analytical results are summarized in Table 4, with the certified values for Ag. It can be seen that the analytical results of Ag closely matched with the certified values and the relative standard deviation (RSD) does not exceed $10 \%$.

Compared with Direct ICP-MS Analysis Methods. Water bath - aqua regia test was performed according to paper. ${ }^{13}$ To estimate the blanks in the full analytical procedure, 10 digestion vessels were subjected to the full pretreatment procedure one time before use. Then, the blank values in the full analytical procedures were measured by ICP-MS with the external calibration for both methods. The detection limit (DL) was calculated as the concentration equivalent of three times the standard deviation of the procedural blank. The blank values and the detection limits were plotted in Figure

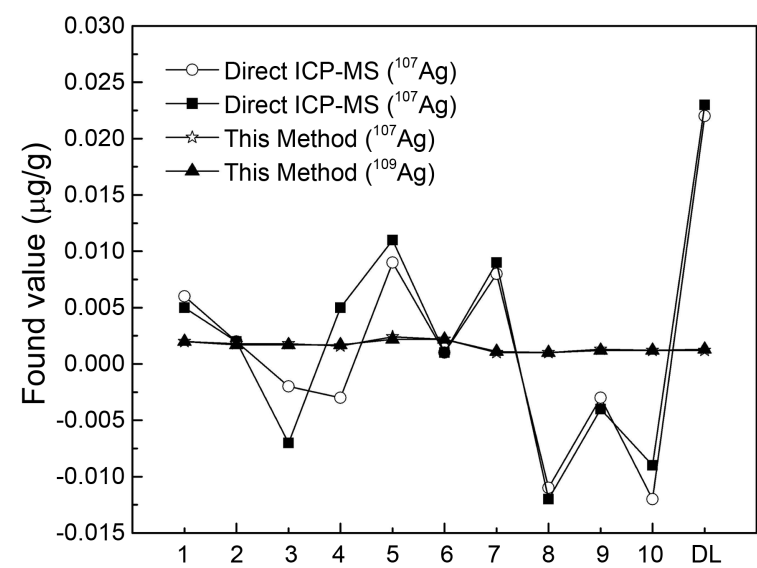

Figure 3. Detection Limit Test.

3. The Ag blank ranged from 1 to $2 \mathrm{ng} / \mathrm{g}$ values that compare favorably with values determined by direct ICP-MS method. Our detection limits were thus sufficiently low relative to the Ag content of all the reference materials analyzed in this work, even for the ultratrace biology samples. This may explain the enrichment separation performed by our method reduced the matrix effect but direct ICP-MS did not eliminate all the interferences. However, other effects like the HCl-thiourea background solution obviously also contributed to the differences of the two methods.

The two methods were then verified by comparing the recognized reference materials, see Table 5 . It can be seen the direct ICP-MS method can accurately determine the

Table 5. Determination of Ag by Direct ICP-MS and This Method

\begin{tabular}{|c|c|c|c|c|c|c|c|c|c|}
\hline \multirow{3}{*}{ Samples } & \multicolumn{4}{|c|}{ Direct ICP-MS } & \multicolumn{4}{|c|}{ This Method } & \multirow[b]{3}{*}{ Certified Value } \\
\hline & \multicolumn{2}{|c|}{${ }^{107} \mathrm{Ag}$} & \multicolumn{2}{|c|}{${ }^{109} \mathrm{Ag}$} & \multicolumn{2}{|c|}{${ }^{107} \mathrm{Ag}$} & \multicolumn{2}{|c|}{${ }^{109} \mathrm{Ag}$} & \\
\hline & Found & Error $\%$ & Found & Error $\%$ & Found & Error $\%$ & Found & Error $\%$ & \\
\hline GBW07401 & 0.352 & 0.57 & 0.346 & 1.14 & 0.349 & 0.33 & 0.349 & 0.33 & 0.35 \\
\hline GBW07402 & 0.057 & 5.56 & 0.059 & 9.26 & 0.044 & 18.56 & 0.044 & 18.56 & 0.054 \\
\hline GBW07103 & 0.023 & 30.30 & 0.024 & 27.27 & 0.022 & 32.58 & 0.024 & 32.58 & 0.033 \\
\hline GBW07604 & 0.022 & 69.23 & 0.023 & 76.92 & 0.0134 & 2.54 & 0.0139 & 2.54 & 0.013 \\
\hline GBW07605 & 0.025 & 38.89 & 0.024 & 33.33 & 0.0188 & 4.17 & 0.0194 & 4.17 & 0.018 \\
\hline
\end{tabular}




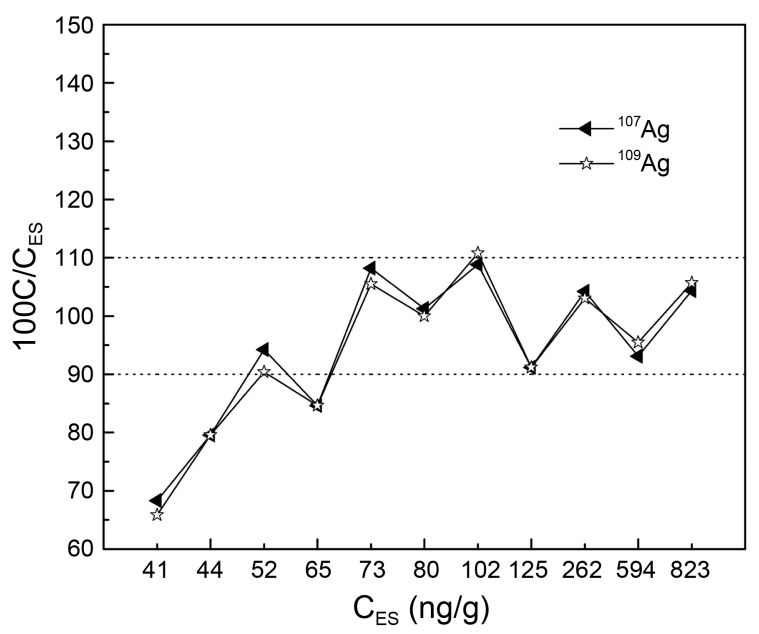

Figure 4. Comparsion of ICP-MS and DC-ARC-AES: $\mathrm{C}_{\mathrm{ES}}$ were $\mathrm{Ag}$ concentrations of the samples determined by DC-ARC-AES, C were ${ }^{107} \mathrm{Ag}$ and ${ }^{109} \mathrm{Ag}$ of the samples found by ICP-MS.

content of $\mathrm{Ag}$ in some selected reference materials. However, for GBW07604 and GBW07605, the test results are bigger than the certified values. This is because the residual of the interferences were more compared with the sulfhydryl cotton enrichment separation. So the back ground value of direct ICP-MS procedure influence the accuracy of the results. However, the errors of GBW07103 for both methods are big. After further experiments, it was proved that the low results was mainly because of the current digestion method was difficult to dissolve the sample completely. Both four acids $\left(\mathrm{HCl}, \mathrm{HF}, \mathrm{HNO}_{3}, \mathrm{HClO}_{4}\right)$ method and closed digestion could reduce the error for our method.

Compared with the DC-ARC-AES Method. 11 geological samples were selected for the comparison, see Figure 4. The ES results were obtained by a geology survey report (Hubei Geology Experiment Research Laboratory). There is no significant difference between the results of relative high concentration samples $\left(\mathrm{C} / \mathrm{C}_{\mathrm{ES}}\right.$ are within $90 \%$ and $\left.110 \%\right)$. However, this method have lower values for samples with less than $44 \mathrm{ng} / \mathrm{g}$ of $\mathrm{Ag}$. It was reported ${ }^{16}$ the detection Limit of DC-ARC-AES is $20 \mathrm{ng} / \mathrm{g}$. Therefore when the concentration of Ag is near $20 \mathrm{ng} / \mathrm{g}$, the result is hardly accurate. On the other hand, the detection limit of our method is much smaller than $41 \mathrm{ng} / \mathrm{g}$. Thus, we could verify the survey report with our method for the Ag values near the detection limit.

\section{Conclusions}

We have provided a method for the accurate measurement of $\mathrm{Ag}$ in geological samples, including ultratrace $\mathrm{Ag}$ in biology samples. This includes sample dissolution, enrichment separation using sulfhydryl cotton columns, and determination with ICP-MS. The interferences are avoided and the memory effect was reduced. For different reference materials (GBW07401, GBW07402, GBW07103, GBW07104, GBW07604, GBW07605), this method gave good reproducibility errors $(\mathrm{RSD}<10 \%)$. The results clearly show the advantages of the method for the determination of low Ag levels in some biology samples. There are no significant differences between relatively high content $\mathrm{Ag}$ samples for the comparison to direct ICP-MS and DC-ARC-AES methods. However, only our method can be proposed for lower $\mathrm{Ag}$ analysis when the determined result is near $20 \mathrm{ng} / \mathrm{g}$.

Acknowledgments. Financial support from China Geology Survey (Grant No. 1212010511218) is gratefully acknowledged.

\section{References}

1. José Bento Borba da Silva, Maârcia Andreia Mesquita da Silva, Adilson Joseâ Curtius, etc., Journal of Analytical Atomic Spectrometry 1999, 14, 1737-1742.

2. Zhou, L.; Li, Z. Chinese Journal of Analytical Chemistry 2005, $24,20-25$.

3. Albina, I. K.; Olga, V. Z.; Olga, A. S. Geostandard and Geoanalytical Research 2007, 31, 251-259.

4. Tang, Y. Q. Geostandards Newsletter 1992, 16, 61-70.

5. Won, M.-S.; Yeom, J.-S.; Yoon, J.-H. Bull Korean Chemical Society 2003, 24, 948-952.

6. Ingrid, M. D.; Daniel, L. G. B. Mikrochimica Acta 2009, 167, 2126.

7. Rizzoa, F.; Cirronea, G. P.; Cuttonea, G. et al., Microchemical Journal 2011, 97(2), 286-290.

8. Argekar, A. A.; Kulkarni, M. J.; Mathur, J. N. et al., Talanta 1995, 42, 1937-1942.

9. Haji Shabani, A. M.; Dadfarnia, S.; Jafari, A. A. et al., Canadian Journal of Analytical Sciences and Spectroscopy 2006, 51(4), 194-199.

10. Albina, I. K.; Nina, L. C. Geostandards Newsletter 2002, 26(3), 307-312.

11. Epov, V. N.; Lariviere, D.; Epova, E. N. et al., Geostand Geoanal Res. 2007, 28, 213-214.

12. Field MP, Sherrell RM. Magnetic sector ICPMS.

13. Newman, A. Analytical Chemistry 1996, 68, 46A-51A.

14. Zhongxi, L.; Liping, Z.; Feng, T. Microchimica Acta 2006, 156(3), 263-269.

15. Gómez, M. M.; Hidalgo García, M. M.; Palacios Corvillo, M. A. Analyst 1995, 120, 1911-1915.

16. Zhu, L.; Liu, H.; Li, Z. et al., Metallurgical Analysis 1991, 4, 2629.

17. Cao, C.; Wei, Y.; Liu, J. Rock and Mineral Analysis 2010, 29, 458460 . 